\title{
Archéopages Archéopages
}

Archéologie et société

$45 \mid 2017$

De la terre au pot

Céramique, habitat et territoires au premier âge du Fer en Bourgogne orientale ( $\mathrm{du} \mathrm{VIII}^{\mathrm{e}}$ au $\mathrm{v}^{\mathrm{e}}$ siècle avant J.-C.)

Régis Labeaune

\section{OpenEdition}

1 Journals

Édition électronique

URL : https://journals.openedition.org/archeopages/3600

DOI : 10.4000/archeopages.3600

ISSN : 2269-9872

Éditeur

INRAP - Institut national de recherches archéologiques préventives

Édition imprimée

Date de publication : 1 mars 2018

Pagination : 144

ISSN : 1622-8545

\section{Référence électronique}

Régis Labeaune, "Céramique, habitat et territoires au premier âge du Fer en Bourgogne orientale (du VIII au ve siècle avant J.-C.) ", Archéopages [En ligne], 45 | 2017, mis en ligne le 01 janvier 2020, consulté le 03 juin 2021. URL : http://journals.openedition.org/archeopages/3600 ; DOI : https:// doi.org/10.4000/archeopages.3600 


\section{NOVEMBRE 2016}

École Pratique des Hautes Études

Directeur de thèse

Stéphane Verger

Directeur d'études, École Pratique des Hautes Études

Membres du jury

Président

Patrice Brun

Professeur, université Paris 1

Panthéon-Sorbonne

Rapporteurs

Anne-Marie Adam

Professeur émérite,

université de Strasbourg

Eugène Warmenbol

Professeur, université libre

de Bruxelles

Examinateurs

Dominique Garcia

Président de l'Inrap

Stefan Wirth

Professeur, université de Bourgogne

Consultable

sous format papier à la bibliothèque de l'École Pratique des Hautes

Études
Régis Labeaune

Inrap, UMR 6298 « ArTeHiS »

\section{Céramique, habitat et territoires au premier âge du Fer en Bourgogne orientale (du vIII ${ }^{\mathrm{G}}$ au v $\mathrm{v}^{\mathrm{e}}$ siècle avant J.-C.).}

Jusque dans les années 1980, le premier âge du Fer en Bourgogne orientale était connu essentiellement par les fouilles des nécropoles tumulaires ou des habitats de hauteur. Les travaux sur les habitats de plaine dans le Dijonnais, quant à eux, très lacunaires, reposaient largement sur des observations réalisées lors de découvertes fortuites. Depuis une vingtaine d'années, le développement des fouilles de l'archéologie préventive (Afan et Inrap), lié aux différents travaux d'aménagement du territoire, a permis d'effectuer de nombreux décapages de grande envergure. Grâce à ces découvertes récentes, les données sur les habitats de plaine de cette période ont considérablement évolué. De ce fait, nos connaissances sur ce type de sites - trop longtemps délaissés au profit des habitats de hauteur et des tumuli dont le mobilier est souvent beaucoup plus prestigieux - ont pu être élargies.

Pour aborder le sujet des habitats de plaine, nous avons choisi les sites les plus caractéristiques et les plus emblématiques, soit en raison de leur surface, soit par le mobilier archéologique recueilli. Le corpus des habitats se compose de 110 sites dont 98 ont été découverts lors d'opérations d'archéologie préventive. Pour la plupart, ces fouilles avaient fait l'objet d'un rapport d'opération mais rarement d'une publication. L'élaboration du catalogue a consisté à reprendre tous les rapports de fouilles pour proposer des monographies homogènes qui puissent être comparées.

Le premier travail a été de dater précisément les habitats. Ainsi, tout le mobilier recueilli sur les sites dont l'occupation était comprise entre le Bronze final et La Tène ancienne a été inventorié. Une typologie précise de la céramique hallstattienne a été réalisée à partir des 250 ensembles clos découverts sur ces habitats de plaine. Ensuite, le mobilier des habitats de hauteur, fouillés anciennement et dont la céramique n'avait jamais été dessinée ni étudiée, a été intégré à cette typo-chronologie. Le résultat obtenu propose une sériation et une évolution du mobilier au cours du premier âge du Fer pour aboutir à la datation des sites présentés dans le corpus.
La deuxième partie visait à caractériser les sites en comparant leur superficie et en étudiant les différents types de structures présentes dans chaque habitat. Ces associations apportent des informations complémentaires sur leur organisation spatiale et leur fonction. Cette partie de l'étude avait pour objectif de proposer une hiérarchisation des différents sites, qu'ils soient de hauteur ou de plaine. La même étude a été réalisée sur les sites funéraires pour comparer les nécropoles tumulaires et celles à enclos. Le dernier chapitre, qui met en relation les sites d'habitats avec les nécropoles, apporte une vision plus complète de l'occupation spatiale de ce territoire.

La troisième partie est consacrée à cette occupation spatiale. La recherche et la documentation archéologique étant très inégales sur l'aire géographique définie initialement, cinq fenêtres, ayant bénéficié de fouilles nombreuses sur d'importantes surfaces de décapage, ont fait l'objet d'une attention particulière. Les conclusions montrent que les habitats correspondent à de petites fermes à vocation rurale en relation avec le développement d'une société agro-pastorale qui occupe ce territoire. La rareté des objets méditerranéens découverts sur les sites témoigne du fait que cette société n'a pas besoin d'exploiter les relations commerciales à grande distance pour subvenir à ses besoins.

La dernière partie du mémoire replace les sites de la Bourgogne orientale dans un contexte français et européen au premier âge du Fer (Bourges, Bragny-sur-Saône, Salins-les-Bains, Lyon, sud du Bassin parisien...). Les différentes comparaisons avec ces autres territoires montrent que cette spécificité agro-pastorale bourguignonne ajoute un modèle à la diversité des occupations observées. Aucune de ces catégories d'habitats ne correspond entièrement au modèle existant dans le Dijonnais. Cependant, le site de Talant « la Peute Combe » pourrait changer cette approche. Ce hameau artisanal est exclusivement consacré à la fabrication de petits objets aussi bien en bronze qu'en fer. La spécialisation de cet artisanat implique l'existence d'un ou de plusieurs habitats plus importants pour diffuser sa production. Des comparaisons ont pu être proposées avec Bourges où le quartier artisanal de « Port Sec Sud » est éloigné de plus de deux kilomètres du « complexe princier » et, également, avec Lyon ou encore la Heuneburg où les quartiers artisanaux se trouvent en périphérie d'un site fortifié. Ces comparaisons viendraient renforcer l'idée de l'existence d'un habitat de taille plus importante localisé probablement sur les premiers reliefs dominant la plaine de la Saône. 